\title{
Analysis of Temperature Characteristics of High- speed Rail Bearings based on Dynamics Model and Thermal Network Method
}

\section{Bao-sen Wang}

Shijiazhuang Tiedao University

Yongqiang Liu ( $\square$ liuyq@stdu.edu.cn )

Shijiazhuang Tiedao University

Bin Zhang

University of South Carolina

\section{Original Article}

Keywords: High-speed train , Axle box bearing , Temperature characteristics , Thermal network method

Posted Date: September 17th, 2021

DOI: https://doi.org/10.21203/rs.3.rs-885689/v1

License: (c) This work is licensed under a Creative Commons Attribution 4.0 International License.

Read Full License 


\section{Title page}

\section{Analysis of temperature characteristics of high-speed rail bearings based on dynamics model and thermal network method}

Bao-Sen Wang, born in 1990, is currently a phD candidate at School of Traffic and Transportation, Shijiazhuang Tiedao University, China. He received his master's degree from Shijiazhuang Tiedao University, China, in 2018. His research interests include dynamics modeling analysis and bearing fault diagnosis of high-speed train bearings.

Tel: +86-13393112382; E-mail: wangbs@stdu.edu.cn

Yong-Qiang Liu, born in 1983, is currently a professor at School of Mechanical Engineering, Shijiazhuang Tiedao University, China. He received his phD degree in vehicle engineering from Beijing Jiaotong University, China, in 2011. His research interests include prognostics and health management, vehicle system dynamics, and smart soft material and damper.

E-mail: liuyq@stdu.edu.cn

Bin Zhang, born in 1972, is currently a associate professor at Department of Electrical Engineering, University of South Carolina, USA. He received his phD degree in electrical engineering from Nanyang Technological University, Singapore, in 2007. His research interests include prognostics and health management, intelligent systems and controls, and their applications to various engineering systems.

E-mail: zhangbin@cec.sc.edu

\section{Corresponding author: Yong-Qiang Liu E-mail: liuyq@stdu.edu.cn}




\title{
Analysis of temperature characteristics of high-speed rail bearings based on dynamics model and thermal network method
}

\author{
Bao-Sen Wang ${ }^{1,3}$ • Yong-Qiang Liu' ${ }^{2}$ Bin Zhang ${ }^{3}$
}

Received June xx, 201x; revised February xx, 201x; accepted March xx, 201x

(C) Chinese Mechanical Engineering Society and Springer-Verlag Berlin Heidelberg 2017

\begin{abstract}
This paper establishes a dynamics model of the axle box bearing of high-speed trains. The model can obtain contact force and its change law. Between rollers and raceway when the bearing contains outer ring faults, inner ring faults, and rolling element faults. Based on the model, the thermal network method is introduced to study the temperature characteristics of axle box bearings of high-speed trains. In this model, the bearing can be divided into some isothermal nodes. The heat generation, conduction, and dispersion of these isothermal nodes can be solved. The results show that the temperature of the contact point between the outer ring raceway and the rolling elements is the highest. By analyzing the relationship between the node and the speed and fault size, it is obtained that the higher the speed, the higher the node temperature. When the fault size increases, the node temperature first increases and then decreases.
\end{abstract}

Keywords: High-speed train - Axle box bearing - Temperature characteristics $\bullet$ Thermal network method

\section{Introduction}

As essential parts of high-speed trains, axle box bearings play a critical role in the safe operation of trains. Temperature is currently the primary safety inspection method for high-speed train axle box bearings. Therefore, it is vital to analyze the influencing factors of temperature characteristics [1]. At present, axle temperature sensors are

Yong-Qiang Liu

liuyq@ stdu.edu.cn

1 School of Traffic and Transportation, Shijiazhuang Tiedao University, Shijiazhuang 050043, China

2 School of Mechanical Engineering, Shijiazhuang Tiedao University, Shijiazhuang 050043, China

3 Department of Electrical Engineering, University of South Carolina, Columbia 29201, USA often installed on trains to monitor the temperature near bearings to determine whether the bearings have faults. Since faults significantly effect temperature, it is essential to study the temperature change law of each part of the bearing under different faults and operating conditions. However, the current research on the relationship between bearing operating state, the operating environment and bearing heating is not enough, especially from dynamics perspective to analyze the impact of bearing fault status on heating. The challenges encountered in this research can be summarized in two aspects.

On the one hand, there are many factors affecting the temperature of each part of the bearing, and the influencing mechanism is complex. On the other hand, during the operation of trains, the external environment and operating conditions are constantly changing, so the temperature is also constantly changing, and is difficult to predict. In order to solve the above two problems, many experts and scholars have made a lot of efforts and made significant progress. Research methods are mainly divided into finite element method and thermal network method.

Choi [2] used the finite element method to investigate the thermal characteristics of the spindle bearing system with a tilting axis so as to improve the performance of the spindle bearing system. The comparison of the numerical results with the experimental results shows that the finite element method well predicts the thermal characteristics of the spindle bearing system. Kucinschi et al. [3] proposed an advanced bi-dimensional model and used the finite element method to calculate the temperature field in a journal bearing. The model takes into account the point-wise variation of viscosity with temperature, as well as the thermal deformations of both spindle and bush. Finally, the theoretical predictions were validated by comparison with 
experimental data. Because the finite element method has good accuracy and can simulate the bearing temperature field well, it is also applied to the analysis of high-speed trains. Tarawneh et al. [4] developed a finite element model for railroad tapered-roller bearings that can obtain the working temperature of the internal parts of the bearing based on the external temperature of the bearing and verified its effectiveness by experiments. Yan et al. [5] established a heat generation model for both raceway and rib of train bearings and employed the finite element method via the APDL program to analyze the bearing's temperature field distribution under conditions of different speeds and loads. Both simulation and experiments show that the rib is critical for the temperature-rise failure of high-speed train bearings. Although the finite element method has high accuracy and can predict the overall temperature distribution of bearings, its calculation speed is slow. In practical applications, more attentions are paid to the temperature of key parts in bearings, which reduces the calculation efficiency of the finite element method. The thermal network method can predict temperature by closely linking the frictional heat, heat transfer relationship of each part of the bearing and the heat dissipation of the surrounding air. It is mainly divided into three steps, determining the isothermal node, calculating the power loss and thermal resistance between each node, and solving. Among them, power losses calculation is the most important step and many scholars have studied the friction heat of bearing systems.

Palmgren [6] has fitted the empirical formula of friction torque calculation through experimental research on bearings of different types and sizes. Nélias [7] took the angular contact ball bearings in the gearbox under radial and axial load conditions as the research object, combined with the pseudo-dynamics model and lubrication model, and gave the calculation method of power loss. Harris et al [8] used the friction torque formula to study the frictional heating power of the rolling elements and raceways of ball bearings and roller bearings under oil lubrication conditions Pouly [9, 10] established a relatively complete thermal network model of angular contact ball bearings under oil and gas conditions. In the power loss, the frictional heat generated by scroll and slide between rollers and raceway, viscous friction on rollers and, slide between cage and ferrule is fully considered. However, the above energy loss models are considered as a whole. During high-speed train running, the contact force on each roller of the axle box bearing is constantly changing and needs to be calculated separately to achieve high fidelity [10]. Barday [12] used the thermal network method to study the heat transfer of truck axles, in which the power loss of gear set is determined by the local friction model. The calculation process of using friction torque to obtain the power loss is complicated. If the model can directly calculate the contact force between the roller and the raceway, more accurate results can be obtained with a greatly simplified solution process [11].

The thermal network model discretizes the bearing system into different isothermal nodes based on the structure. There are different heat transfer relationships between these isothermal nodes, which can be divided into three types: heat conduction, heat convection and heat radiation. Because the heat transfer relationship between thermal network nodes is very complicated, a simplified model is used to calculate the thermal resistance between nodes. Eckert [13] studied the thermal convection relationship between the inner and outer rings of the bearing and the lubricating oil. Ma et al. [14] studied the thermal convection relationship between the spindle and the air using the theory of convective heat dissipation from a rotating cylinder. Jakob et al. [15] determined the surface heat transfer coefficient when forced heat convection occurs between the air outside the bearing housing and the outer surface of the bearing housing at a certain speed. In terms of heat conduction, bearing seats, bearing rings, and spindles are all cylindrical or cylindrical entities along the radius. This type of one-dimensional heat conduction problem can be simplified as a single-layer cylindrical wall heat conduction problem [16]. Ai [17] established the formula for heat resistance between rolling elements and raceway of the bearings. Muzychka et al [18] studied the thermal resistance of the elliptical contact area and considered the influence of contact area size and motion state on thermal resistance. In terms of air heat resistance, Meng et al. [19] provided a theoretical solution on the thermal resistance of sealed air layer and took the residential double-glazed glass as an example to determine its optimal thermal resistance value.

The thermal grid method has been continuously studied with more and more applications since its inception. In 1974, Shaberth first developed a thermal calculation program for the US military, which can calculate the temperature distribution and thermodynamics behavior of a spindle system containing up to five rolling bearings, and this program was updated and optimized in 1981 [120]. Then Dowson et al. [21] demonstrated a thermal network analysis method applied to a $110 \mathrm{~mm}$ diameter ring-oiled journal bearing.

Mezani et al. [22] presented a coupling model to describe the electromagnetic and thermal phenomena of an 
induction motor in which the thermal analysis part was conducted by using the thermal network method. Although these works explained the analysis process of the thermal network method very well, it is equally important to study the influence of external conditions on bearing temperature. $\mathrm{Ai}$ et al. [17] established a thermal network model for double-row tapered roller bearings, which are widely used in high-speed train, based on generalizing Ohm's law. The model calculates the sliding friction loss and viscous drag loss of the rollers-inner ring, rollers-outer ring and roller large-end-flange in detail and considers many factors that can affect the bearing temperature, such as contact force, grease, angular speed, oil film thickness and so on. Ma et al [23] developed a mathematical model of grease-lubricated spherical roller bearings and used the thermal network method to analyze the temperature characteristics. The results indicate that rotation speed, radial load and grease filling rate are positively related to bearing temperature. Zheng et al. [24] developed a comprehensive thermal network model for a pair of front bearings of high-speed spindle and their surroundings to forecast the temperature rise of bearings and introduced the heat transfer path in bearings in detail. Especially, the influence of the bearing thermal strain on the bearing force balance when calculating the heat generation was considered in the model Experimental results show that the model is effective.

These existing works use the thermal network method to simulate and analyze the bearing temperature. However, they are all based on static or pseudo-static models. During the operation of high-speed trains, the working conditions are constantly changing, and the temperature of the bearings is also constantly changing. Furthermore, they do not consider the impact of bearing faults and fault size on temperature analysis, which is very important for highspeed trains. Meanwhile, the atmospheric environment near the bearing is simplified. Actually, due to the high speed of trains, the air near the bearing is divided into two parts, the air near the spindle and the air near the axle box. Their temperatures are also different. In order to solve the above problems, this paper proposes a dynamics and temperature coupling model for the axle box bearing of a high-speed train, in which the air near the axle box bearing is divided into two parts. At the same time, the model can describe the dynamics behavior and temperature changes of the bearings with different fault sizes. Inadequately, the model is only for the temperature at equilibrium points, i.e., the model cannot describe the whole progress, which can be future work.

The paper is organized as follows: Section 1 illustrate the research status of the two methods of temperature field analysis and the calculation steps of the thermal network method. Section 2 describes the process of building a double-row tapered rolling bearing model. Section 3 takes the high-speed train bearing dynamics model as the carrier, explains in detail the calculation steps of the thermal network method, and uses this method to obtain the temperature of each part of the bearing. Section 4 analyzes the influence of bearing speed, fault type and fault size on temperature, compares the real high-speed train axle temperature data and simulation results and proves the validity of the model.

\section{Dynamics model}

\subsection{Bearing model}

The running part of a high-speed train consists of an axle, a left wheel, and a right wheel. According to the law of conservation of energy, the axle mass is equivalent to the axle center of mass [25]. Figure 1 shows the structure of the axle box bearing of high-speed trains, in which $O_{1}, O_{2}, O_{3}$ is the bearing geometry center, center of spindle section and center of mass of spindle section, respectively; e is the eccentricity of cross-section of the spindle, $\mathrm{mc}$ is the equivalent mass $(\mathrm{kg})$ of the spindle at the center; $K, C$ is the stiffness and damping of the spindle, respectively; $F_{x \mathrm{~L}}, F_{y \mathrm{~L}}$ is the reaction force $(\mathrm{N})$ received by the left end bearing in the horizontal and vertical directions, respectively, $F_{x \mathrm{R}}, F_{\mathrm{yR}}$ is the reaction force $(\mathrm{N})$ received by the right end bearing in the horizontal and vertical directions, respectively, and $\alpha$ and $\beta$ is the contact angle and the half cone angle given in degree, respectively.

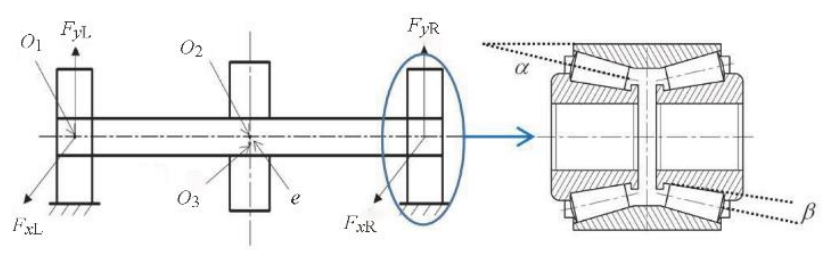

Figure 1 Spindle and bearing coupling system model

Figure 2 shows the schematic diagram of bearings dynamics model, in which $m_{1}, m_{2}, m_{\mathrm{b}}$ is the masses $(\mathrm{kg})$ of the bearing inner ring, bearing and unit resonator, respectively; $x 1, y 1$ is displacement $(\mathrm{m})$ of the left row inner ring in the horizontal and vertical directions, respectively; $K_{1}, C_{1}$ is support stiffness $(\mathrm{N} / \mathrm{m})$ and support damping $(\mathrm{N} \cdot \mathrm{s} / \mathrm{m})$ of the inner ring, respectively; $x_{2}, y_{2}$ is the displacement $(\mathrm{m})$ of the outer ring in the horizontal and vertical directions, respectively; $K_{2}, C_{2}$ is the support 
stiffness $(\mathrm{N} / \mathrm{m})$ and support damping $(\mathrm{N} \cdot \mathrm{s} / \mathrm{m})$ of the outer ring, respectively; $y_{\mathrm{b}}, K_{\mathrm{b}}, C \mathrm{~b}$ is the vertical displacement $(\mathrm{m})$, stiffness $(\mathrm{N} / \mathrm{m})$ and damping $(\mathrm{N} \cdot \mathrm{s} / \mathrm{m})$ of the unit resonator, respectively. The bearing in Figure 2 is considered as a model that is coupled with a series of spring-mass models and is simulated by establishing a set of differential equations according to Newton's second law.

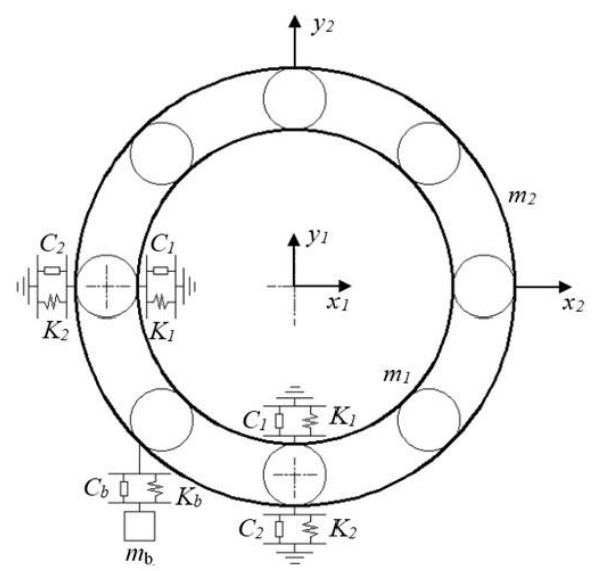

Figure 2 Spring mass system of simplified bearing

When a fault occurs, the periodic impact of the fault leads to natural vibration of bearing inner and outer rings and other components [26, 27]. The vibrations can be accurately simulated by adjusting the stiffness and damping coefficient of the unit resonator. According to Newton's second law, the dynamics of a bearing-rotor system can be described as:

$$
\begin{aligned}
& \mathrm{I}\left\{\begin{array}{l}
m_{\mathrm{c}}+C x_{\mathrm{c}}+K\left(x_{\mathrm{c}}-x_{\mathrm{r} 1}\right)+K\left(x_{\mathrm{c}}-x_{11}\right)=m_{\mathrm{c}} e w_{\mathrm{c}}^{2} \cos \left(w_{\mathrm{c}} t\right) \\
m_{\mathrm{c}}+C y_{\mathrm{c}}+K\left(y_{\mathrm{c}}-y_{\mathrm{r} 1}\right)+K\left(y_{\mathrm{c}}-y_{11}\right)=m_{\mathrm{c}} e w_{\mathrm{c}}^{2} \cos \left(w_{\mathrm{c}} t\right) \\
-m_{\mathrm{c}} g
\end{array}\right. \\
& \mathrm{II}\left\{\begin{array}{l}
m_{1}+C_{1} \&_{\mathrm{T}}+K_{1} x_{\mathrm{r} 1}+F_{\mathrm{xR}} \cos (\alpha-\beta)=0 \\
m_{1}+C_{1} \&_{\mathrm{r} 1}+K_{1} y_{\mathrm{r} 1}+F_{\mathrm{yR}} \cos (\alpha-\beta)=0 \\
m_{2}+C_{2} \&_{\mathrm{r} 2}+K_{2} x_{\mathrm{r} 2}-F_{\mathrm{xR}} \cos (\alpha+\beta)=0 \\
m_{2}+\left(C_{2}+C_{\mathrm{b}}\right) \&_{\mathrm{r} 2}+\left(K_{2}+K_{\mathrm{b}}\right) y_{\mathrm{r} 2}-K_{\mathrm{b}} y_{\mathrm{b}}-C_{\mathrm{b}} \& \\
-F_{\mathrm{yR}} \cos (\alpha+\beta)=F \cos (\alpha+\beta)
\end{array}\right. \\
& \text { III }\left\{m_{\mathrm{b}}+C_{\mathrm{b}}\left(\&_{\mathrm{rb}}^{\&}-K_{\mathrm{r} 2}\right)+K_{\mathrm{b}}\left(y_{\mathrm{rb}}-y_{\mathrm{r} 2}\right)=0\right. \\
& \mathrm{IV}\left\{\begin{array}{l}
m_{1}+C_{1}+K_{1} x_{11}+F_{\mathrm{xL}} \cos (\alpha-\beta)=0 \\
m_{1}+C_{1} \& K_{1} y_{11}+F_{\mathrm{yL}} \cos (\alpha-\beta)=0 \\
m_{2}+C_{2}+K_{2} x_{12}-F_{\mathrm{xL}} \cos (\alpha+\beta)=0 \\
m_{2}+\left(C_{2}+C_{\mathrm{b}}\right)+\left(K_{2}+K_{\mathrm{b}}\right) y_{12}-K_{\mathrm{b}} y_{\mathrm{b}}-C_{\mathrm{b}} \& \\
-F_{\mathrm{yL}} \cos (\alpha+\beta)=F \cos (\alpha+\beta)
\end{array}\right. \\
& \mathrm{V}\left\{m_{\mathrm{b}}+C_{\mathrm{b}}\left(\&_{\mathrm{rb}}-K_{\mathrm{b}}\right)+K_{\mathrm{b}}\left(y_{\mathrm{bb}}-y_{12}\right)=0\right.
\end{aligned}
$$

Where $K, C$ is support stiffness and support damping of the shaft, respectively; $x_{\mathrm{c}}, y_{\mathrm{c}}$ is the displacement of centroid of the shaft in the horizontal and vertical directions, respectively; $x_{11}, x_{12}, y_{11}, y_{12}$ is for the left end bearing; $y_{\mathrm{rb}}, y_{1 \mathrm{~b}}$ is the displacement of the unit resonator at right and left end in the vertical direction, respectively; $F$ is the axle load of a train. In this model, Equation. I is the vibration equations of the shaft in the horizontal and vertical directions, equation. II is the vibration equations of the right-end bearing in the horizontal and vertical directions, equation. IV is the vibration equations of the left end bearing in the horizontal and vertical directions, equations. III and V are the vibration equations of the unit resonator in the vertical direction.

\subsection{Bearing support reaction force}

In the model, bearing support reaction force is needed. However, the magnitude and direction of the force change with the rotation of the bearing. The force can be calculated as follows:

- Calculating the contact force on each other.

- Decomposing the force into the forward direction and radial direction of the bearing.

- Combine all the forces in the above two directions and the bearing support reaction force can be obtained in these two directions.

Since the forces on the inner and outer rings of bearings are transmitted through the rollers in bearing movement, the reaction force is the sum of the resultant force of the contact forces at each roller. In practice, the motion state and force of bearings are very complicated. To simplify the calculations, the following assumptions are introduced. Note that these assumptions are commonly used and do not lower the accuracy and fidelity of the model.

- The outer ring of bearings is fixed on the rigid element with a rotating velocity of 0 and it has lateral and vertical displacements.

- The rolling elements are equidistantly located on the raceway and perform pure rolling (i.e., sliding of rolling elements are not considered).

- The contact stress is considered in the form of Hooke's law. 


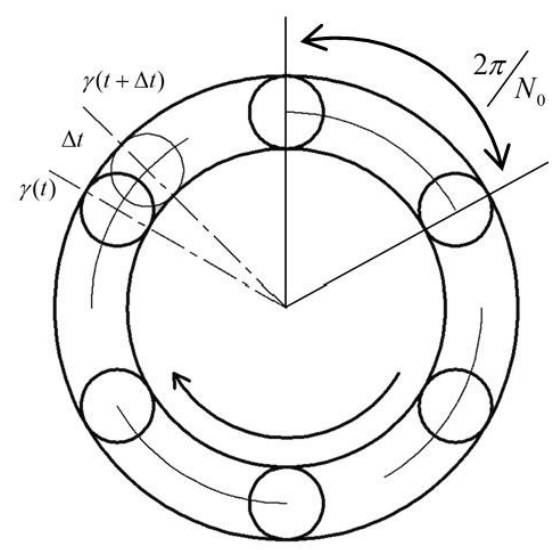

Figure 3 Side view of a double-row tapered roller bearing

Figure 3 shows the side view of a double-row tapered roller bearing with N0 rollers that equally separated by an angle of $2 \pi / N_{0}$, In the rotating operation, the angle of the $i$ th roller $\left(i=1,2, \ldots, N_{0}\right)$ turns at time t can be calculated as:

$$
\theta_{i}=\gamma(t)+\frac{2 \pi}{N_{0}}(i-1), i=1,2, \mathrm{~L}, N_{0}
$$

Where $\gamma(\mathrm{t})$ is the angle that the roller indexed by 1 turns in time $t$, and its initial location is $\gamma\left(t_{0}\right)=0$. The normal contact deformation of the $i$-th roller of the right end bearing with the raceway at the angular displacement $\theta_{i}$ can be calculated as:

$$
\delta_{i}=\left(x_{r 1}-x_{r 2}\right) \cos \theta_{i}+\left(y_{r 1}-y_{r 2}\right) \sin \theta_{i}-c_{0}
$$

Where $c_{0}$ is the bearing radial clearance. The contact force between the ball and the raceway can be expressed by the nonlinear Hertz's contact force as [27]:

$$
P_{i}=K_{t} \delta_{i}^{n} H_{i}
$$

Where $K_{\mathrm{t}}$ is the contact stiffness, $n=10 / 9$. When $\delta_{i}>0, H_{i}$ $=1$ and it indicates that there is a nonlinear Hertz's contact force while $\delta_{i}<0, H_{i}=0$ indicates that there is no nonlinear Hertz's contact force. By decomposing the contact force at every roller into the horizontal and vertical directions, the resultant force in the two directions can be obtained. The total contact force of the bearing in the horizontal and vertical directions is the sum of the resultant force from all rollers, which is given as:

$$
\left\{\begin{array}{l}
F_{x R}=K_{t} \sum_{i=1}^{N_{0}} \delta_{i}^{\frac{10}{9}} H_{i} \cos \theta_{i} \\
F_{y R}=K_{t} \sum_{i=1}^{N_{0}} \delta_{i}^{\frac{10}{9}} H_{i} \sin \theta_{i}
\end{array}\right.
$$

Where $F_{\mathrm{xR}}, F_{\mathrm{yR}}$ is the contact force in horizontal and vertical directions, respectively, for the right-end bearing. Similarly, $F_{\mathrm{xL}}, F_{\mathrm{yL}}$ for the left-end bearing can be obtained.

\subsection{Parameter of system}

Select the axle box bearing of a certain type of high-speed train as the research object. Table 1, 2, 3 list the main parameters of the high-speed EMU axle box bearing, the rotor system, and the unit resonator in the simulation.

Table 1. The parameter of the bearing

\begin{tabular}{ll}
\hline Parameter & Value of parameter \\
\hline Inner ring mass $m_{1}(\mathrm{~kg})$ & 4.63 \\
Inner ring radius $r(\mathrm{~mm})$ & 6.5 \\
Total bearing mass $m_{2}(\mathrm{~kg})$ & 30 \\
Outer ring radius $R(\mathrm{~mm})$ & 120 \\
Number of rollers $N_{0}$ & 17 \\
Contact angle $\alpha\left(^{\circ}\right)$ & 10 \\
Half-cone angle $\beta\left({ }^{\circ}\right)$ & 1.7 \\
Bearing rolling element diameter $d(\mathrm{~mm})$ & 26.5 \\
Bearing pitch meter $D(\mathrm{~mm})$ & 156.25 \\
Axle load $F(\mathrm{~N})$ & $2.0205 \times 10^{4}$ \\
\hline
\end{tabular}

Table 2. The parameter of the bearing system model

\begin{tabular}{ll}
\hline Parameter & Value of parameter \\
\hline Equivalent mass at shaft centre $\mathrm{mc}(\mathrm{kg})$ & 274 \\
Bending damping of shaft $\mathrm{C}(\mathrm{N} \cdot \mathrm{s} / \mathrm{m})$ & $2 \times 10^{6}$ \\
Bending stiffness of shaft $\mathrm{K}(\mathrm{N} / \mathrm{m})$ & $1.48 \times 10^{7}$ \\
Mass eccentricity of shaft section e $(\mathrm{mm})$ & $10^{-5}$ \\
Inner ring damping coefficient $\mathrm{C} 1(\mathrm{~N} \cdot \mathrm{s} / \mathrm{m})$ & $7 \times 10^{4}$ \\
Inner ring stiffness coefficient $\mathrm{K} 1(\mathrm{~N} / \mathrm{m})$ & $3.05 \times 10^{8}$ \\
Outer ring damping coefficient $\mathrm{C} 2(\mathrm{~N} \cdot \mathrm{s} / \mathrm{m})$ & $7 \times 10^{4}$ \\
Outer ring stiffness coefficient $\mathrm{K} 2(\mathrm{~N} / \mathrm{m})$ & $2 \times 10^{10}$ \\
Contact stiffness coefficient $\mathrm{Kt}(\mathrm{N} / \mathrm{m})$ & $3.5 \times 10^{10}$ \\
\hline
\end{tabular}

Table 3. The parameter of the unit resonator

\begin{tabular}{ll}
\hline Parameter & Value of parameter \\
\hline Vibration mass $m_{\mathrm{b}}(\mathrm{kg})$ & 1 \\
Stiffness coefficient $\mathrm{Kb}(\mathrm{N} / \mathrm{m})$ & $8.8826 \times 10^{9}$ \\
Damping coefficient $\mathrm{Cb}(\mathrm{N} \cdot \mathrm{s} / \mathrm{m})$ & $9.424 \times 10^{3}$ \\
\hline
\end{tabular}




\section{Thermal network method of bearing}

\subsection{Isothermal nodes division}

The bearing system is assembled with different parts. It is assumed that in the heat transfer process, the temperature at different positions of the same part is equal. Based on this, the bearing can be divided into several isothermal nodes, as shown in figure 4(a) and table 4.

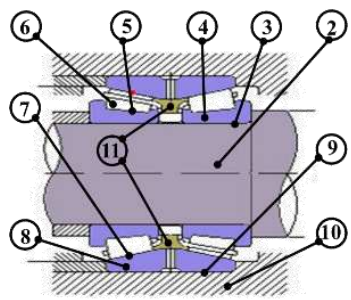

(a) Isothermal nodes

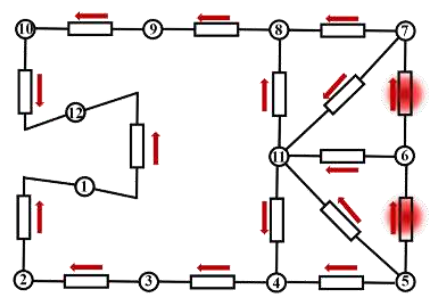

(b) Thermal resistance network
Figure 4 Bearing isothermal node division and heat transfer path

Table 4 Isothermal nodes

\begin{tabular}{ll}
\hline Temperature of nodes & Name of nodes \\
\hline$T_{1}$ & Air around spindle \\
$T_{2}$ & Spindle \\
$T_{3}$ & Spindle $\cap$ inner ring \\
$T_{4}$ & Inner ring \\
$T_{5}$ & Inner ring $\cap$ rolling elements \\
$T_{6}$ & Rolling elements \\
$T_{7}$ & Outer ring $\cap$ rolling elements \\
$T_{8}$ & Outer ring \\
$T_{9}$ & Outer ring $\cap$ axle box \\
$T_{10}$ & Axle box \\
$T_{11}$ & Grease \\
$T_{12}$ & Air around axle box \\
\hline
\end{tabular}

$\mathrm{A} \cap \mathrm{B}=$ Contact point of $\mathrm{A}$ and $\mathrm{B}$

Among them, the contact point between the two contact objects of the bearing is also regarded as an isothermal node. According to the Hertz contact theory, the friction loss between the roller and the raceway is generated in a small area, whose size is much smaller than the diameter of the roller. This phenomenon limits the flow of heat from the contact area to the center of the contact body. That is, there is a 'bottleneck' of heat conduction between the surface of the bearing element and the main body [29]. According to $[9,10]$, the high-temperature zone of bearing components is mainly concentrated on a very thin layer on the surface, while the temperature of the main body is relatively low. At the same time, the bogie is constructed like a container with its opening facing down, through which the air around the spindle is enclosed and isolated from the air around the axle box. Therefore, the air around the spindle and the air around the axle box is regarded as two different isothermal nodes.

In the system, heat is transferred between adjacent nodes that are connected with thermal resistance. In bearing operations, Part of the heat generated inside the bearing is absorbed by the grease, and the other part is transmitted through various parts of the bearing, and finally dissipated into the air. The direction of heat flow is shown in figure 4(b). The thermal resistance is defined by generalized Ohm's law as:

$$
R=\frac{\Delta T}{Q}
$$

Where $R$ is the thermal resistance, $\Delta T$ is the temperature difference and $Q$ is heat flow between two adjacent nodes, respectively. The generalized schematic diagram of thermal resistance is shown in figure 5 .

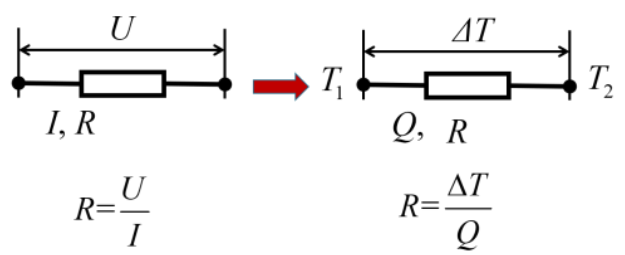

Figure 5 The popularization principle of thermal resistance

\subsection{Contact force analysis under fault conditions}

The calculation of contact force is the basis of model establishment and temperature field analysis. Existing works [5, 30, 31] show that when a rolling element passes through a fault area, the change of the deformation will cause sudden changes of contact force, as shown in figure 6 . At the same time, an impact force will be generated and modelled $[32,33]$. It can be seen that when a fault exists in the bearing, the contact force will undergo a sudden change and an additional impact force will be generated to further increase the contact force. Based on the model established in the paper, the resultant force of the contact force (referred to as contact force here and after) between the rolling elements and the raceway can be obtained when the bearing has an outer ring fault, an inner ring fault, and a rolling element fault, as shown in figure 7. In this simulation, the fault size $L_{0}$ is $1 \mathrm{~mm}$, and the bearing inner ring speed $w_{\mathrm{c}}$ is $1600 \mathrm{r} / \mathrm{min}$. 


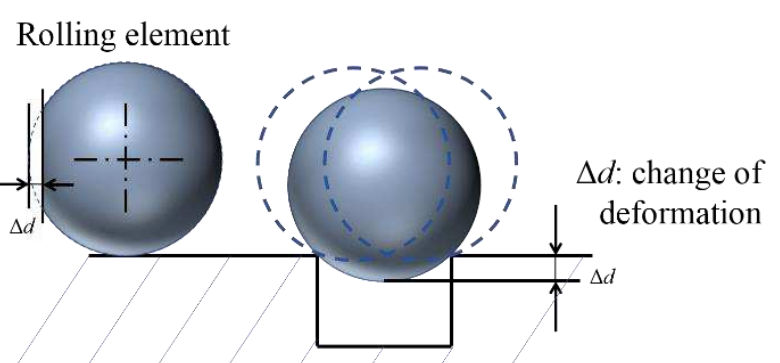

Bearing ring

Figure 6 Change of deformation

Denote the characteristic fault frequency of bearing as $f_{\mathrm{BPFO}}, f_{\mathrm{BPFI}}$ and $f_{\mathrm{BSF}}$ for faults on the outer ring, inner ring, and rolling element, respectively. Each time a rolling element passes through the fault area, the contact force will change. The interval time of the contact force change $t_{\mathrm{cit}}$ is the same as the interval time for the rolling element passing through the fault area. Furthermore, the rolling elements will contact the fault edge when entering the fault area and leaving the fault area, as shown in figure 6, which causes two sudden changes in the contact force, and the time of the two sudden changes $t_{\text {sct }}$ is proportional to the width of the fault. However, when the bearing has a rolling element fault, the edge of the fault area is always in contact with the raceway. In this case, the deformation and contact force do not change during this process. For the bearing used in the simulation, we have the following results.

When the bearing has an outer ring fault:

$$
\left\{\begin{array}{l}
t_{c i t}=\frac{1}{f_{\mathrm{BPFO}}}=0.0053 \mathrm{~s} \\
t_{s c t}=\frac{N_{0} \arcsin \left(\frac{L_{0}}{2 r_{0}}\right) t_{c i t}}{\pi}=4.78 \times 10^{-4} \mathrm{~s}
\end{array}\right.
$$

When the bearing has an inner ring fault:

$$
\left\{\begin{array}{l}
t_{c i t}=\frac{1}{f_{\mathrm{BPFI}}}=0.0037 \mathrm{~s} \\
t_{s c t}=\frac{N_{0} \arcsin \left(\frac{L_{0}}{2 r_{0}}\right) t_{c i t}}{\pi}=1.7 \times 10^{-4} \mathrm{~s}
\end{array}\right.
$$

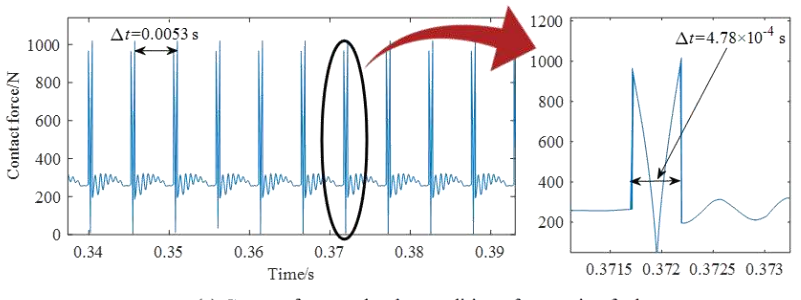

(a) Contact force under the condition of outer ring fault

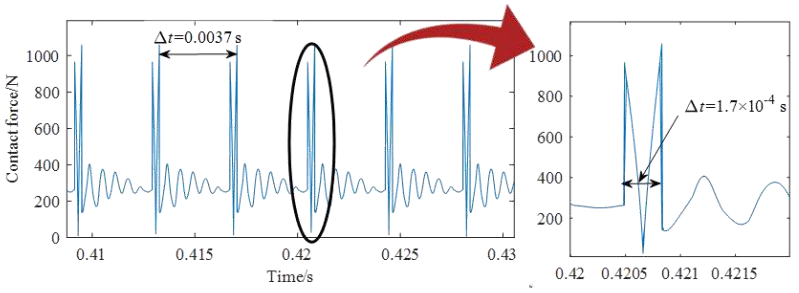

(b) Contact force under the condition of inner ring fault

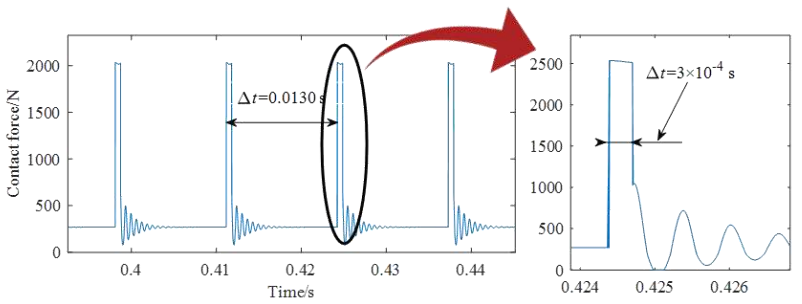

(c) Contact force under the condition of rolling element fault

Figure 7 Resultant force of contact force between rolling elements and raceway

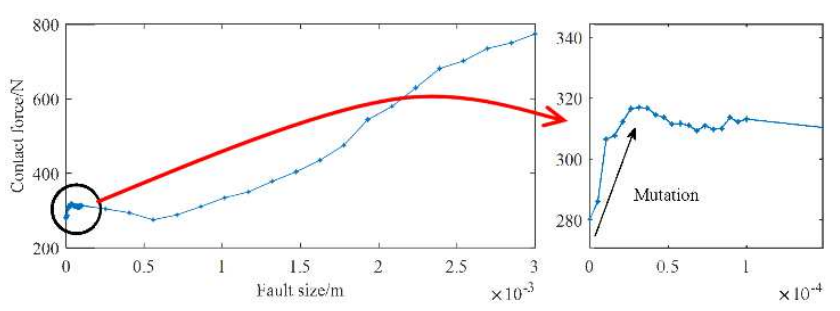

(a) Outer ring fault

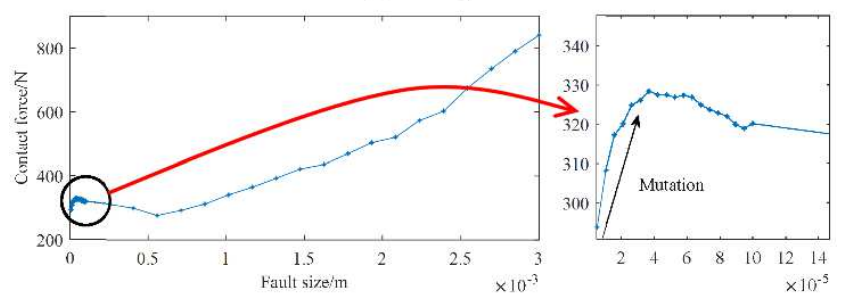

(b) Inner ring fault

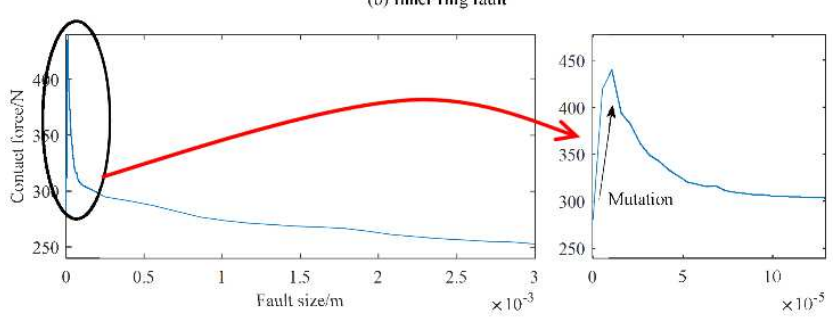

(c) Rolling element fault

Figure 8 Relationship between contact force and fault size 
When the bearing has a rolling element fault:

$$
\left\{\begin{array}{l}
t_{c i t}=\frac{1}{f_{\mathrm{BSF}}}=0.013 \mathrm{~s} \\
t_{s c t}=\frac{N_{0} \arcsin \left(\frac{L_{0}}{2 r_{0}}\right) t_{c i t}}{\pi}=3 \times 10^{-4} \mathrm{~s}
\end{array}\right.
$$

The comparison between equation. (7) - (9) and figure 7 shows that the simulation results and the theoretical calculation results are consistent.

When the bearing speed is constant, the contact force $P$ changes periodically within a certain period of time. Under the law of conservation of energy, it can be replaced by the average value of the contact force in a period. Figure 8 shows the equivalent contact force changes when the fault size changes. It can be seen from figure 8 that when the bearing has no fault, the contact force is usually relatively small. With the presence of a fault, the contact force will change suddenly due to the existence of the impact force. As the size of the fault increases, the contact force also increases. Among them, when the bearing has a rolling element fault, the change in contact force is more obvious, and its characteristics are different from other fault scenarios. As the size of the rolling element fault increases, the contact force drops rapidly after a sudden change, and then gradually decreases. The reason is that the fault area will become smoother as the width of the fault increases, making the impact force smaller, so the contact force will also be smaller.

The internal power loss of rolling bearings is mainly caused by the mutual friction of the internal components of the bearing. This friction, including the friction between the rolling elements and the raceways of the inner and outer rings, and the friction between the rolling elements and the cage, is also the main reason for the increase in bearing temperature. Because the dynamics model in this paper ignores abnormal bearing behaviors such as roller slip and cage shaking, only the former friction is considered when calculating the energy loss, and the latter form of friction is equivalent to the contact force. In most cases, friction torque is used to calculate the energy loss inside the bearing and get the total heat generation of the bearing as a whole. However, the position of each roller of the bearing and the force are different. It is more reasonable and easier to use the local method [11]. In this method, the heat generation of each roller is calculated separately and then summed to the overall heat generation of the bearing. The heat generation of each roller is calculated as follows:

$$
q_{i}=\mu P_{i} v_{i}
$$

Where $q_{i}$ is the total frictional heat generation at the $i$-th roller, $\mu$ is the rolling friction coefficient between roller and raceway and $v_{i}$ is the relative speed of roller and raceway. The overall heat generation is given as:

$$
Q=\sum_{i=1}^{N_{0}} q_{i}
$$

\subsection{Thermal resistance}

The heat transfer in the bearing rotor system includes conduction heat transfer, convection heat transfer and heat radiation. Since the heat transfer by thermal radiation is much smaller than the other two, it can be ignored.

\subsubsection{Conduction heat transfer}

Heat conduction is a process in which a large number of molecules, atoms or electrons collide with each other, and energy is transferred from a relatively higher temperature part of an object to a lower temperature part or from a hightemperature object to a low-temperature object.

(a) The bearing spindle, inner ring, outer ring, and axle box can be simplified as cylinders with inner and outer ring radii of $r_{\text {in }}$ and $r_{\text {ex }}$ respectively. This kind of heat conduction relationship can be simplified as a one-dimensional heat conduction problem along the radius [16], and the thermal resistance can be calculated as:

$$
R=\frac{\ln r_{e x}-\ln r_{i n}}{2 \pi k L}
$$

Where $k$ is thermal conductivity and $L$ is characteristic length. Thermal resistance between ' $T_{2} \& T_{3}$ ', ' $T_{3} \& T_{4}$ ', ' $T_{8} \& T_{9}$ ' and ' $T_{9} \& T_{10}$ ' in Fig. 4 and Table 3 , can be determined by equation. (12).

(b) The contact between the roller and the raceway is Hertz contact, and the size of the contact area is much smaller than the size of the bearing. The thermal resistance of this part can be calculated as [18]:

$$
R=\frac{1}{\pi}\left(\frac{a}{b}\right) \frac{1}{k a \sqrt{P e}}
$$

Where $a$ is the semi-major axis of the ellipse along the rolling direction, $b$ is the semi-minor axis of the ellipse perpendicular to the rolling direction, and $P e$ is the Peclet 
number. Equation. (13) is used to determine the thermal resistance between ' $T_{4} \& T_{5}$ ', ' $T_{5} \& T_{6}$ ', ' $T_{6} \& T_{7}$ ' and ' $T_{7} \& T_{8}$ ' in figure 4 and table 4.

\subsubsection{Convection heat transfer}

Thermal convection is the heat exchange between the fluid and the solid when the fluid flows over the solid surface. Heat convection is the most difficult form of heat transfer to quantify. In the bearing system, heat is transferred from the bearing to the lubricant, and then from the lubricant to the bearing seat and other components. There is also thermal convection between the outer surface of the bearing and the surrounding fluid, which is usually air. In most cases, convection thermal resistance can be expressed by:

$$
R=\frac{1}{A h_{c}} \frac{1}{A}\left(\frac{L}{k N u}\right)
$$

Where $A$ is the surface area of the contact surface where heat exchange occurs, $k$ is the thermal conductivity of the fluid, $L$ is the characteristic length, and $N u$ is dimensionless Nusselt number, which is determined by different convection conditions as follows.

(a) The part of the spindle extending beyond the bearing has a convective heat dissipation relationship with the air, and the $\mathrm{Nu}$ is calculated as follows:

$$
N u=\left\{\begin{array}{cc}
0.00308 R e+4.432 & R e<7300 \\
R e^{0.37} & 7300 \leq R e<9600 \\
30.5 R e^{-0.0042} & R e \geq 9600
\end{array}\right.
$$

Where $R e=V D_{\mathrm{s}} / v_{\text {air }}$, in which $v_{\text {air }}$ is kinematic viscosity of air, $V$ is spindle line speed and $D_{\text {s }}$ is diameter of spindle. Equation. (15) is used to determine the thermal resistance between ' $T_{1} \& T_{2}$ ' in figure 4 and table. 4 .

(b) When the bearing ring rotates, it exchanges heat with the grease. The heat transfer relationship can be simplified as a concentric rotating cylinder model [34]. In this case, $\mathrm{Nu}$ is calculated as follows:

$$
N u=\left\{\begin{array}{cc}
2 & T a<41 \\
0.167 T a^{0.69} \operatorname{Pr}^{0.4} & 41 \leq T a<100 \\
0.401 T a^{0.5} \operatorname{Pr}^{0.4} & T a \geq 100
\end{array}\right.
$$

Where $T_{a}=\rho \varepsilon_{R} \sqrt{\varepsilon_{R} r_{\text {ring }}} / \nu_{\mathrm{g}}$ in which $\varepsilon_{\mathrm{R}}$ is the radial clearance between inner and outer rings, $r_{\text {ring }}$ is the internal radius of the ring and $v_{\mathrm{g}}$ is the kinematic viscosity of grease.
Equation. (16) is used to determine the thermal resistance between ' $T_{4} \& T_{11}$ ', ' $T 5 \& T_{11}$ ', ' $T_{6} \& T_{11}$ ', ' $T_{7} \& T_{11}$ ' and ' $T_{8} \& T_{11}$ ' in figure 4 and table. 4 .

(c) When the train is moving, the air blows over the surface of the axle box at the speed of the train, which will cause forced convection to dissipate heat. The surface heat transfer coefficient $h_{\mathrm{c}}$ can be approximate as:

$$
h_{c}=0.03 \frac{k}{D_{h}}\left(u_{s} D_{h} / v_{\text {air }}\right)^{0.57}
$$

Where $k$ is air thermal conductivity, $D_{\mathrm{h}}$ is the outer diameter of the axle box.

Since air is a fluid, there is a natural convection heat dissipation between air and the axle box. In this case, $\mathrm{Nu}$ can be determined by equation. (15). Assuming that the equivalent thermal resistance of air and axle box is $R$, the resistance of forced convection heat dissipation is $R_{1}$, and the resistance of natural convection heat dissipation is $R_{2}$, then we have

$$
\frac{1}{R}=\frac{1}{R_{1}}+\frac{1}{R_{2}}
$$

Equation. (18) can be used to determine the thermal resistance between ' $T_{10} \& T_{12}$ ' in figure 4 and table. 4 .

\subsubsection{Heat transfer in the enclosed air layer}

Under normal circumstances, high-speed trains travel very fast, which reduces the efficiency of heat exchange between the air near the spindle of the bogie and the outside atmosphere. The air near the spindle will appear to be confined in a closed space and is isolated from the outside atmosphere by an air layer. The air near the spindle will dissipate the heat absorbed from the spindle to the outside atmosphere through the air layer. The thermal resistance between ' $T_{1} \& T_{12}$ ' in figure 4 and table 4 can be calculated by:

$$
R=\frac{d_{\mathrm{air}}}{\lambda_{a}+\lambda_{c}+\lambda_{r}}
$$

where $d_{\text {air }}$ is the enclosed air layer thickness, $\lambda_{\mathrm{a}}$ is the thermal conductivity of the air layer, $\lambda_{c}$ is the convective equivalent thermal conductivity of the air layer and $\lambda_{\mathrm{r}}$ is the Radiation equivalent thermal conductivity of the air layer. 


\subsection{Node temperature solution}

In electricity, the nodal current law states that the sum of currents flowing into a node is equal to the sum of currents flowing out of that node. Similarly, in a thermal grid, the sum of heat flowing into a node is equal to the sum of heat flowing out of that node. The equivalent schematic diagram is shown in figure 9. In particular, additional heat is generated near the rolling elements due to friction, the heat relationship at the relevant nodes is:

$$
\sum Q_{\mathrm{in}}+\sum Q_{f}-\sum Q_{\text {out }}=0
$$

Where $Q_{\text {in }}$ is the input heat, $Q_{\text {out }}$ is the output heat and $Q_{\mathrm{f}}$ is the heat from the friction.

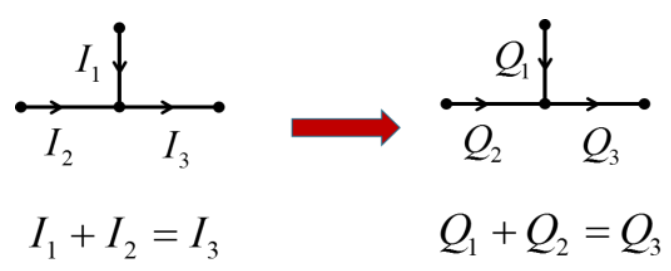

Figure 9 Derivation of heat relationship principle

According to the generalized Ohm's law, Equation. (20) can be used to determine the heat flow relationship at each node in the thermal network and finally obtain a set of equations representing the direction of heat flow in the bearing rotor system. The thermal resistance between the two nodes is distinguished by the node number, while $c$ means the heat transfer by the conduction, and $v$ means the heat transfer by the convection. For example, $R_{3 \mathrm{c} 2}$ represents the conduction thermal resistance between $T_{3}$ and $T_{2}$ and heat flows from $T_{3}$ to $T_{2}$. Similarly, $R_{6 \mathrm{v} 11}$ represents the convection thermal resistance between $T_{6}$ and $T_{11}$ and heat flows from $T_{6}$ to $T_{11}$. The thermal resistance of the enclosed air layer is $R_{\text {air }}$. Based on the above analysis, the heat transfer in the bearing system can be described as follows:

$$
\left\{\begin{array}{l}
\frac{T_{1}-T_{12}}{R_{\mathrm{air}}}-\frac{T_{2}-T_{1}}{R_{2 \mathrm{v} 1}}=0 \\
\frac{T_{2}-T_{1}}{R_{2 \mathrm{v} 1}}-\frac{T_{3}-T_{2}}{R_{3 \mathrm{c} 2}}=0 \\
\frac{T_{3}-T_{2}}{R_{3 \mathrm{c} 2}}-\frac{T_{4}-T_{3}}{R_{4 \mathrm{c} 3}}=0 \\
\frac{T_{4}-T_{3}}{R_{4 \mathrm{c} 3}}-\frac{T_{11}-T_{4}}{R_{11 \mathrm{v} 4}}-\frac{T_{5}-T_{4}}{R_{5 \mathrm{c} 4}}=0 \\
\frac{T_{5}-T_{4}}{R_{5 \mathrm{c} 4}}+\frac{T_{5}-T_{11}}{R_{5 \mathrm{v} 11}}+\frac{T_{5}-T_{6}}{R_{5 \mathrm{cc}}}=1 /\left(2 Q_{\mathrm{i}}\right) \\
\frac{T_{6}-T_{11}}{R_{6 \mathrm{vv} 11}}-\frac{T_{5}-T_{6}}{R_{5 \mathrm{c} 6}}-\frac{T_{7}-T_{6}}{R_{7 \mathrm{cc} 6}}=1 /\left(2 Q_{\mathrm{i}}\right)+1 /\left(2 Q_{\mathrm{o}}\right) \\
\frac{T_{7}-T_{8}}{R_{7 \mathrm{cc} 8}}+\frac{T_{7}-T_{11}}{R_{7 \mathrm{v} 11}}+\frac{T_{7}-T_{6}}{R_{7 \mathrm{cc} 6}}=1 /\left(2 Q_{\mathrm{o}}\right) \\
\frac{T_{8}-T_{9}}{R_{8 \mathrm{c} 9}}-\frac{T_{11}-T_{8}}{R_{11 \mathrm{v} 8}}-\frac{T_{7}-T_{8}}{R_{7 \mathrm{c} 8}}=0 \\
\frac{T_{9}-T_{10}}{R_{9 \mathrm{c} 10}}-\frac{T_{8}-T_{9}}{R_{8 \mathrm{c} 9}}=0 \\
\frac{T_{10}-T_{12}}{R_{10 \mathrm{v} 12}}-\frac{T_{9}-T_{10}}{R_{9 \mathrm{c} 10}}=0 \\
\frac{T_{11}-T_{4}}{R_{11 \mathrm{v} 4}}+\frac{T_{11}-T_{8}}{R_{11 \mathrm{v} 8}}-\frac{T_{7}-T_{11}}{R_{7 \mathrm{c} 11}}-\frac{T_{6}-T_{11}}{R_{6 \mathrm{vv} 11}}-\frac{T_{5}-T_{11}}{R_{5 \mathrm{v} 11}}=0
\end{array}\right.
$$

Where $Q_{\mathrm{i}}$ and $Q_{\mathrm{o}}$ is the heat generated by the friction between the rolling elements and the raceway of the inner ring and outer ring, respectively. The temperature of the outside atmosphere $T_{12}$ is a constant in this paper. In equation. (21), there are 11 equations and 11 unknowns. The temperature of each node can be obtained by using the Gauss-Seidel iteration method [35].

\section{Results and discussion}

\subsection{Effect of speed on temperature}

When the train is running, the speed often changes, which also causes the change of the temperature of various parts in the bearing. In order to describe this phenomenon, the bearing dynamics model and thermal grid model are used to obtain the temperature of each node of the bearing and its change with speed. In order to illustrate the influence of bearing speed temperature, the temperature at each node under the condition of no-fault and the bearing angular speed of $1600 \mathrm{r} / \mathrm{min}$ is obtained by simulation, as shown in table. 5. Node $T_{12}$, the temperature of the air around the axle box is given as $T_{12}=20^{\circ} \mathrm{C}$. 
Table 5 Isothermal nodes

\begin{tabular}{cccc}
\hline $\begin{array}{c}\text { Node } \\
\text { number }\end{array}$ & $\begin{array}{c}\text { Node temperature } \\
\left({ }^{\circ} \mathrm{C}\right)\end{array}$ & $\begin{array}{c}\text { Node } \\
\text { number }\end{array}$ & $\begin{array}{c}\text { Node temperature } \\
\left({ }^{\circ} \mathrm{C}\right)\end{array}$ \\
\hline$T_{1}$ & 32.43 & $T_{7}$ & 92.86 \\
$T_{2}$ & 81.07 & $T_{8}$ & 69.13 \\
$T_{3}$ & 81.64 & $T_{9}$ & 58.53 \\
$T_{4}$ & 81.97 & $T_{10}$ & 53.24 \\
$T_{5}$ & 88.81 & $T_{11}$ & 79.81 \\
$T_{6}$ & 86.96 & $T_{12}$ & 20 \\
\hline
\end{tabular}

It can be seen from table 5 that the temperature of nodes $T_{5}-T_{7}$ is relatively higher. The reason is that the heat generated by the internal friction of the bearing is radiated from the vicinity of the rolling elements. At the same time, since the grease $\left(T_{11}\right)$ absorbs part of the heat generated by the friction, its temperature is also very high. Among them, temperature of node $T_{7}$ is the highest because the outer ring bears a lot of loads from the car body. The temperature of the air around the axle box $\left(T_{12}\right)$ is an important part of the thermal grid, which directly or indirectly affects the temperature of the components of the bearing rotor system. Figure 10 shows the temperature change of some representative nodes with the temperature of the air around the axle box.

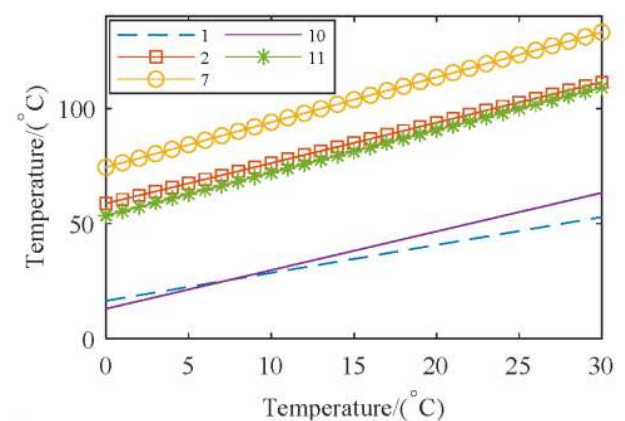

Figure 10 Node temperature change with the temperature of the air around axle box

It can be seen from figure 10 that the outside air temperature, i.e., the temperature of the air around the axle box, has a linear relationship with the temperature of the system components. This eliminates the interference of outside atmospheric temperature when analyzing the influence of other factors on the temperature of each component. The running speed of the train has an important influence on temperature. Figure 11 shows the temperature change of some representative nodes with the train running speed.

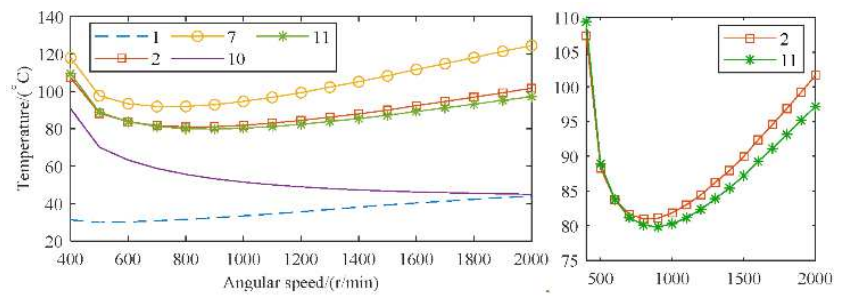

Figure 11 Node temperature change with the train running speed

It can be seen from figure 11 that as the train speed increases, the convection heat dissipation between the box body and the surrounding air accelerates. As a result, the heat generated by the internal friction of the bearing is quickly transferred to the external environment, causing the internal temperature of the bearing to decrease gradually. However, when the train speed is greater than about 800 $\mathrm{r} / \mathrm{min}$, the heat generated by friction cannot be dissipated opportunely into the air through air convection, making the internal temperature of the bearing gradually rise. Therefore, when the train speed is higher than $800 \mathrm{r} / \mathrm{min}$, the higher the train speed, the higher the temperature of each bearing component. The difference is that the temperature of the axle box $\left(T_{10}\right)$ keeps decreasing as the speed of the train increases. The reason is that the relative speed between the train and the outside air increases so that the heat in the box is dissipated into the air faster through convection. Furthermore, the lower the speed, the higher the temperature of the grease, and the higher the speed, the higher the temperature of the spindle, which means that as the train speed increases, more heat inside the bearing is transferred to the air through various components, and the heat absorbed by the grease decreases. This is evidenced by the growing temperature of the air near the spindle.

\subsection{Effect of fault on temperature}

In addition to speed, the type of bearing fault and the size of the fault also have a significant effect on temperature. Based on the temperature of $T_{7}$, a comparative analysis under different types of faults and different speed conditions is made, as shown in figure 12(a), and a comparative analysis under the conditions of different fault sizes and the bearing angular speed of $1600 \mathrm{r} / \mathrm{min}$ is made, as shown in figure 12(b). 


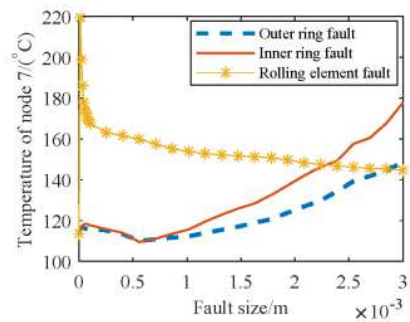

(a) Temperature change with fault size

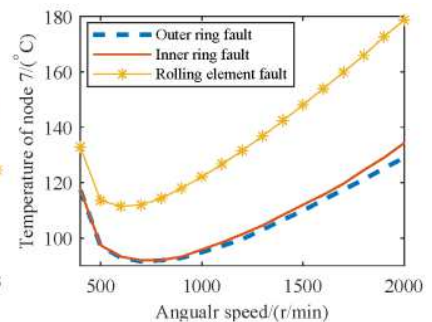

(b) Temperature change with angular speed
Figure 12 Change of temperature with different conditions

It can be seen from figure 12(a) that compared with outer ring faults and inner ring faults, the temperature of $T_{7}$ is more sensitive to rolling element faults. Once the rolling element fails, its temperature will rise sharply. As the size of the fault becomes larger, the faulted edge will be smoother. Therefore, the contact force gradually decreases, and the temperature drops as well. When the bearing fault has a small size (approximately less than $0.6 \mathrm{~mm}$ ) on outer ring and inner ring, the temperature change is almost the same. When the fault size is large, the temperature increases with the increase of the fault size. Moreover, under the condition of the inner ring fault, the temperature rises faster. It can be seen from figure 12(b) that as the bearing speed increases, the temperature under the three fault conditions first drops and then rises. Under the condition of the rolling element fault, the temperature is the highest. Under the condition of outer ring fault and inner ring fault, the temperature is almost the same. The results demonstrate that the temperature is very sensitive to speed, and it is more sensitive to rolling element faults.

\subsection{Verification of actual train axle temperature}

In order to verify the thermal coupling bearing dynamics model established in this paper, real temperature data of a certain type of high-speed EMU and simulation results are used for comparative analysis. The data includes the temperature of the bearing outer ring and spindle. During the operation of the train, the data acquisition instrument samples the temperature and speed once every $30 \mathrm{~s}$, i.e., with a sampling frequency of $1 / 30 \mathrm{~Hz}$. In the data preprocessing, some invalid data and abnormal values are deleted. As a result, the time axis is not continuous, and the number of data points is also different. For example, there are 33 data points in figure 13(b), and data points in figure 14(b). In the simulation, the bearing has no fault, and the bearing rotating speed is the train running speed. In addition, when the train speed is 0 , in the real environment, the temperature of each part of the bearing will gradually drop to the outside temperature. In the simulation model, when there is no heat input, the temperature of each part of the bearing will eventually be equal to the outside temperature. So, in the simulation, when the train is stationary, the temperature of each part of the bearing is regarded as the outside temperature. The comparison analysis of bearing outer ring $\left(T_{8}\right)$ temperature is shown in figure 13 and the comparative analysis of spindle $\left(T_{2}\right)$ temperature is shown in figure 14.

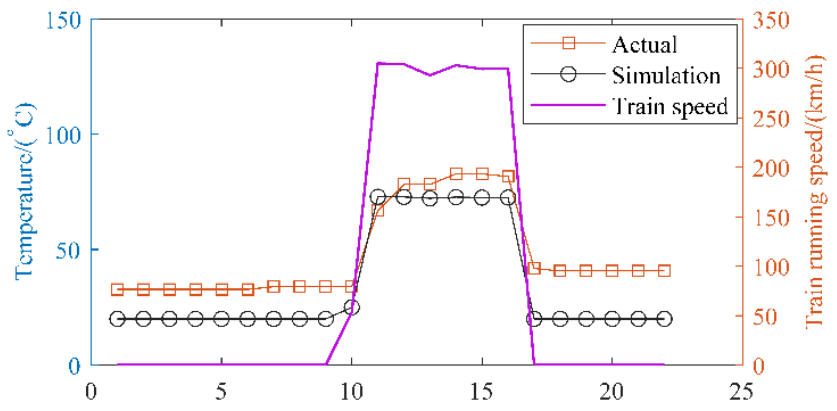

(a)

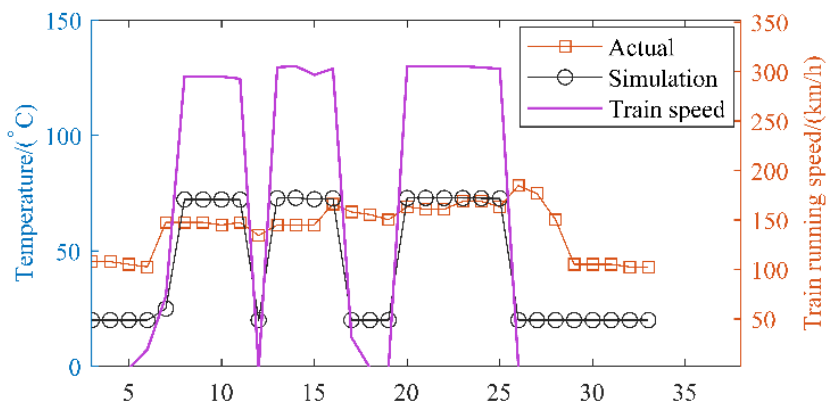

(b)

Figure 13 Comparison analysis of outer ring temperature

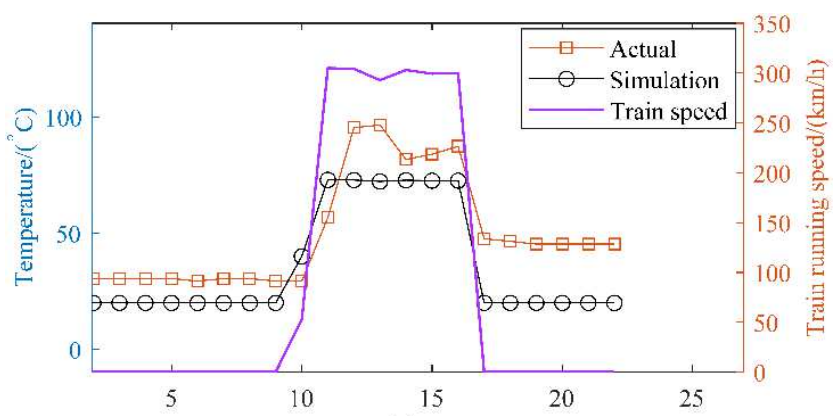

(a)

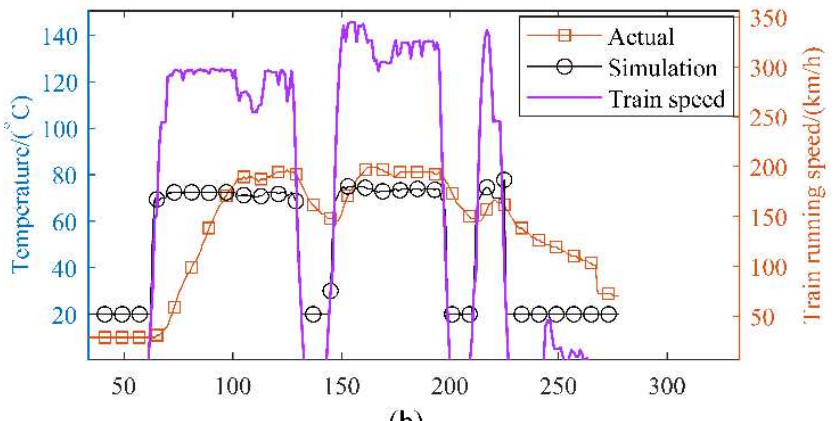

(b)

Figure 14 Comparison analysis of spindle temperature 
Figure 13 and figure 14 show the comparison of actual temperature data and simulation results. When the speed of the train increases, both the actual collected temperature and the simulated temperature rise rapidly. When the speed of the train decreases, both of them gradually decrease. When the train speed is 0 , the actual train bearing temperature slowly drops to the ambient temperature. In this period of time, the actual temperature is higher than the simulation result. The reason is that the model only simulates the final state of bearing temperature. In figure 13(a) and figure 14(a), since the heat production and heat dissipation in the bearing system has not yet reached the equilibrium state during the continuous operation of the train, the temperature appears to continue to rise during this period. In figure 13(b) and figure 14(b), when the train is stationary, the temperature of the outer bearing ring gradually decreases. Then, before the temperature reaches the outside temperature, the train restarts and the temperature goes up. Since the model only simulates the final state of the temperature, it cannot fully describe the temperature change process. This will be one of our future works.

\section{Conclusions}

The paper establishes a dynamics model of bearing rotor systems of high-speed trains and analyzes the contact force changes when the bearing has outer ring fault, inner ring fault and rolling element fault. A thermal grid model of high-speed train bearing rotor systems is established, and the power loss is obtained by the local method. The simulation results of the model show that the temperature of the contact point between the outer ring and the rolling elements is the highest, and the relationship between the temperature of the contact point and the type of fault, the size of the fault and the speed of the bearing spindle is further analyzed. Under no-failure conditions, the bearing temperature data collected by real high-speed EMUs and the simulation results are used for comparative analysis. The results prove the validity of the model. However, the model developed can only simulate the final temperature when the bearing temperature reaches the equilibrium state. Our future work will focus on a development of the model that can describe the dynamics temperature process.

\section{Declaration}

\section{Acknowledgements}

The authors sincerely thank to X Gu, W Liu, W Huai, J
Zhao and L Zhang for their work on the fault-bearing experiment of a high-speed train. Many thanks to the anonymous reviewers, who provided valuable feedback and recommendations.

\section{Funding}

Supported by the National Key R\&D Program (SQ2020YFB200123), National Natural Science Foundation of China (Nos. 11790282,12032017,11802184, 11902205 and 12002221), S\&T Program of Hebei (20310803D), and Natural Science Foundation of Hebei Province (No A2020210028), Postgraduates Innovation Foundation of Hebei Province (CXZZBS2019154), and State Foundation for Studying Abroad.

\section{Availability of data and materials}

The datasets supporting the conclusions of this article are included within the article.

\section{Authors' contributions}

The author' contributions are as follows: Bao-Sen Wang was in charge of Conceptualization, Methodology, Coding, Writing-Original draft and Editing; Yong-Qiang Liu did the work of Validation, Resources, Writing-Reviewing and Editing; Bin Zhang assisted with Conceptualization, Resources, Investigation, Writing-Reviewing and Editing.

\section{Competing interests}

The authors declare no competing financial interests.

\section{Consent for publication}

Not applicable

\section{Ethics approval and consent to participate}

Not applicable

\section{References}

[1] A L Wang, J G Wang. Temperature distribution and scuffing of tapered roller bearing[J]. Chinese Journal of Mechanical Engineering, 2014, 27(6): 1272-1279.

[2] J K Choi. Thermal characteristics of the spindle bearing system with a gear located on the bearing $\operatorname{span}[\mathrm{J}]$. International Journal of Machine Tools and Manufacture, 1998, 38(9): 1017-1030.

[3] B R Kucinschi, M Fillon, J Fréne, et al. A transient thermoelastohydrodynamics study of steadily loaded plain journal bearings using finite element method analysis[J]. Journal of Tribology, 2000, 122(1): 219-226.

[4] C M Tarawneh, A A Fuentes, J A Kypuros, et al. Thermal modeling of a railroad tapered roller bearing using finite element analysis[J]. Journal of Thermal Science and Engineering Applications, 2012, 4(3): 031002.

[5] K Yan, N Wang, Q Zhai, et al. Theoretical and experimental investigation on the thermal characteristics of double-row tapered 
roller bearings of high-speed locomotive[J]. International Journal of Heat and Mass Transfer, 2015, 84: 1119-1130.

[6] A Palmgren.: Ball and roller bearing engineering. Philadelphia: SKF Industries Inc, 1959.

[7] D Nelias, P Sainsot, L Flamand. Power loss of gearbox ball bearing under axial and radial loads@[J]. Tribology transactions, 1994, 37(1) $83-90$.

[8] T Harris, M Kotzalas, N Michael: Rolling Bearing Analysis: Advanced Concepts of Bearing Technology, Boca Raton: CRC Press, 2007.

[9] F Pouly, C Changenet, F Ville, et al. Investigations on the power losses and thermal behavior of rolling element bearings[J]. Proceedings of the Institution of Mechanical Engineers, Part J: Journal of Engineering Tribology, 2010, 224(9): 925-933.

[10] F Pouly, C Changenet, F Ville, et al. Power loss predictions in highspeed rolling element bearings using thermal networks[J]. Tribology Transactions, 2010, 53(6): 957-967.

[11] W C Tang, M J Wang, G D Chen. Analysis on temperature distribution of failure axle box bearings of high-speed $\operatorname{train}[\mathrm{J}]$. Journal of the China Railway Society, 2016, 38(7): 50-56.

[12] D Barday, C Fossier, C Changenet, et al. Investigations on drive axle thermal behaviour: power loss and heat-transfer estimations[J]. SAE International Journal of Engines, 2018, 11(1): 55-66.

[13] Eckert E R G. Introduction to the Transfer of Heat and Mass. New York: McGraw-Hill, 1950.

[14] H T Ma, W Y Zhou, X Y Lu, et al. Investigation on the air flow and heat transfer from a horizontal rotating cylinder[J]. International Journal of Thermal Sciences, 2015, 95: 21-28.

[15] M Jakob, G A Hawkins, et al. Elements of heat transfer and insulation, 2nd ed. New York: John Wiley \& Sons, Inc, 1950.

[16] J P Holman. Heat transfer (Si Units) Sie. 10th ed. Tata McGraw-Hill Education Pvt. Ltd, 2011.

[17] S Y Ai, W Z Wang, Y L Wang, et al. Temperature rise of doublerow tapered roller bearings analyzed with the thermal network method[J]. Tribology International, 2015, 87: 11-22.

[18] Y S Muzychka, M M Yovanovich. Thermal resistance models for non-circular moving heat sources on a half space[J]. Journal of Heat Transfer, 2001, 123(4): 624-632.

[19] Q L Meng, N Cai, Q G Chen. A theoretical solution on the thermal resistance of sealed air layer[J]. Journal of South China University of Technology: Natural Science Edition, 1997, 4: 116-119.

[20] G B Hadden, R J Kleckner, M A Ragen, et al. Steady state and transient thermal analysis of a shaft bearing system including ball, cylindrical and tapered roller bearing[J]. NASA technical paper, 1981 254.

[21] D Dowson, A O Mian, C M Taylor. Paper XIX (i) Thermal network analysis of a ring-oiled bearing and comparison with experimental results[J]. Tribology Series, 1987, 11: 579-586.

[22] S Mezani, N Takorabet, B Laporte. A combined electromagnetic and thermal analysis of induction motors[J]. IEEE transactions on Magnetics, 2005, 41(5): 1572-1575.

[23] F B M, Z M Li, S C Qiu, et al. Transient thermal analysis of grease lubricated spherical roller bearings[J]. Tribology International, 2016, 93: $115-123$.

[24] D X Zheng, W F Chen. Effect of structure and assembly constraints on temperature of high-speed angular contact ball bearings with thermal network method[J]. Mechanical Systems and Signal Processing, 2020, 145: 106929.

[25] Y Q Liu, B S Wang, S P Yang. Nonlinear dynamics behaviors analysis of bearings rotor system with outer ring faults in the high- speed train[J]. Journal of Mechanical Engineering, 2018, 54(8): 1725.

[26] S H Zhou, G Q Song, Z H Ren, et al. Nonlinear dynamic analysis of coupled gear-rotor-bearing system with the effect of internal and external excitations[J]. Chinese Journal of Mechanical Engineering, 2016, 29(2): 281-292.

[27] D Z Zhao, J H Li, W D Cheng, et al. Generalized demodulation transform for bearing fault diagnosis under nonstationary conditions and gear noise interferences[J]. Chinese Journal of Mechanical Engineering, 2019, 32(1): 1-11.

[28] Y Qin, F L Cao, Y Wang, et al. Dynamics modelling for deep groove ball bearings with local faults based on coupled and segmented displacement excitation[J]. Journal of Sound and Vibration, 2019, 447: 1-19.

[29] T A Harris, M N Kotzalas. Advanced concepts of bearing technology: rolling bearing analysis.5th ed. Boca Raton: CRC press, 2006.

[30] S A McInerny, Y Dai. Basic vibration signal processing for bearing fault detection[J]. IEEE Transactions on education, 2003, 46(1): 149-156.

[31] A Rafsanjani, S Abbasion, A Farshidianfar, et al. Nonlinear dynamics modeling of surface defects in rolling element bearing systems[J]. Journal of Sound and Vibration, 2009, 319(3-5): 1150-1174.

[32] S Khanam, J K Dutt, T N andon. Impact force-based model for bearing local fault identification[J]. Journal of Vibration and Acoustics, 2015, 137(5): 051002.

[33] M J Zhang, T J ang, X M Zhang, et al. Intelligent diagnosis of short hydraulic signal based on improved EEMD and SVM with few lowdimensional training samples[J]. Chinese Journal of Mechanical Engineering, 2016, 29(2): 396-405.

[34] I S Bjorklund, W M Kays. Heat transfer between concentric rotating cylinders[J]. Journal of Heat Transfer, 1959, 81(3): 175-183.

[35] Y M Xu, M M Ai, Y Yang. Heat transfer characteristic research based on thermal network method in submersible motor[J]. International Transactions on Electrical Energy Systems, 2018, 28(3): e2507.

\section{Biographical notes}

Bao-Sen Wang, born in 1990, is currently a phD candidate at School of Traffic and Transportation, Shijiazhuang Tiedao University, China. He received his master's degree from Shijiazhuang Tiedao University, China, in 2018. His research interests include dynamics modeling analysis and bearing fault diagnosis of high-speed train bearings.

Tel: +86-13393112382; E-mail: wangbs@stdu.edu.cn

Yong-Qiang Liu, born in 1983, is currently a professor at School of Mechanical Engineering, Shijiazhuang Tiedao University, China. He received his phD degree in vehicle engineering from Beijing Jiaotong University, China, in 2011. His research interests include prognostics and health management, vehicle system dynamics, and smart soft material and damper.

E-mail: liuyq@stdu.edu.cn

Bin Zhang, born in 1972, is currently an associate professor at Department of Electrical Engineering, University of South Carolina, USA. He received his phD degree in electrical engineering from Nanyang Technological University, Singapore, in 2007. His research interests include prognostics and health management, intelligent systems and controls, and their 
applications to various engineering systems.

E-mail: zhangbin@cec.sc.edu 